Edu Consilium: Jurnal BK Pendidikan Islam

Vol 2, No. 1, Februari 2021, hlm. 36 - 47

\title{
EFEKTIVITAS BIMBINGAN KELOMPOK UNTUK MENINGKATKAN KETERAMPILAN KOMUNIKASI SISWA SMK DENGAN TEKNIK ASSERTIVE TRAINING
}

\author{
Anggi Pratama Putri ${ }^{1 *}$, Sri Rizqi Wahyuningrum ${ }^{2}$ \\ ${ }^{1,2}$ Bimbingan dan Konseling Pendidikan Islam, Fakultas Tarbiyah, IAIN Madura \\ *e-mail: anggipratama1299@gmail.com
}

\begin{tabular}{l}
\hline \hline Keywords: \\
group guidance, \\
assertive training, \\
communication skill
\end{tabular}

\begin{abstract}
The research aimed at examining the effectiveness of group guidance in improving communication skills of the SMK by using assertive training techniques. The subjects studied is students of SMK Kesehatan Nusantar who had low levels of communication skills. This research is limited to the use of Assertive Training Techniques to help improve communication skills of students of SMK. The data collection method used was the scale of communication skills. This study used a one-group pretest-posttest experimental design. The results showed that there were differences in the level of communication skills of students before and after receiving group guidance training intervention with assertive training techniques which were analyzed using the paired sample t-test. In addition, this study has a different mean value. This shows that the success of the treatment carried out can vary in interval of increase depending on conditions and problems that occur in the field. Group guidance training interventions with assertive training techniques are effective in improving communication skills of students of Vocational School.
\end{abstract}

Kata Kunci:

Bimbingan Kelompok, latihan asertif, Keterampilan Komunikasi

\section{Abstrak:}

Penelitian ini bertujuan untuk mengetahui kefektifan bimbingan kelompok dalam meningkatkan ketarampilan komunikasi siswa SMK dengan menggunakan teknik assertive training Subjek yang diteliti adalah siswa SMK yang memiliki tingkat keterampilan komunikasi rendah. Penelitian ini terbatas pada penggunaan Teknik Assertive Training untuk membantu meningkatkan keterampilan komunikasi siswa SMK. Metode pengumpulan data yang digunakan adalah skala keterampilan komunikasi. Penelitian ini menggunakan rancangan eksperimen one-group pretestposttest. Hasil penelitian menunjukkan bahwa ada perbedaan tingkat keterampilan komunikasi siswa sebelum dan sesudah mendapatkan intervensi pelatihan bimbingan kelompok dengan teknik assertive training yang dianalisis menggunakan uji paired sample t-test. Selain itu, penelitian ini memiliki nilai rata-rata yang diperoleh berbeda. Hal ini menunjukkan bahwa keberhasilan perlakuan yang dilakukan dapat berbeda-beda interval peningkatannya bergantung kondisi serta permasalahan yang terjadi di lapangan. Intervensi pelatihan bimbingan kelompok dengan teknik assertive training efektif dalam meningkatkan keterampilan komunikasi siswa SMK. 


\section{PENDAHULUAN}

Salah satu keterampilan yang perlu dimiliki di era revolusi keempat ini salah satunya adalah keterampilan komunikasi. Komunikasi lebih melihat dari perilaku dan tindakan oleh satu orang atau lebih, yang terjadi dalam konteks tertentu serta memiliki pengaruh tertentu dan memiliki kesempatan untu melakukan umpan balik. Komunikasi adalah penyampaian informasi dari satu individu ke individu lain dengan tujuan agar orang lain bisa mendapat pengetahuan dan bisa saling mempengaruhi. Komunikasi pada dasarnya dilakukan dengan menggunakan kata-kata yang mudah dipahami oleh kedua individu, karena dengan komunikasi perasaan seseorang atau sekelompok orang bisa dipahami oleh individu lain. Komunikasi sangat berperan penting dalam kehidupan sehari-hari karena sebagai makhluk sosial kita senantiasa untuk selalu bersosialisasi (komunikasi) dengan individu lain, maka komunikasi yang baik perlu diciptakan agar tercipta keselarasan serta mencegah konflik antar masyarakat satu dengan masyarakat lainnya. Farid (2013) secara umum konflik antar masyarakat dapat terjadi karena adanya kesalahpahaman antar individu satu dengan yang lain. Terjadinya kesalahpahaman ini lah yang menyebabkan tujuan atau misi dari komunikasi tidak tercapai. Oleh karena itu untuk menciptakan komunikasi yang baik juga perlu adanya pelatihan keterampilan komunikasi yang bisa dilakukan secara personal atau berkelompok.

Pelatihan komunikasi di sekolah bisa dilakukan siswa dengan kegiatan diskusi atau dengan bimbingan kelompok. Dalam proses bimbingan kelompok siswa dapat latihan untuk berkomunikasi dan berinteraksi dengan teman-teman kelasnya. Bimbingan kelompok juga akan meningkatkan rasa solidaritas dan kerja sama antar sesama karena dalam bimbingan kelompok siswa akan dilatih menghadapi suatu tugas dan memecahkan tugas tersebut bersama-sama. Dengan demikian akan tercipta komunikasi dengan siswa lain. Layanan bimbingan kelompok merupakan suatu cara memberikan bantuan (bimbingan) kepada individu (siswa) melalui kegiatan kelompok. Dalam layanan bimbingan kelompok, aktivitas, dan dinamika kelompok harus diwujudkan untuk membahas berbagai hal yang berguna bagi pengembangan atau pemecahan masalah individu (siswa) yang menjadi peserta layanan (Tohirin, 2014)

Menurut Tuckman fase pertumbuhan kelompok ada empat yaitu : pertama, tahap pembentukan rasa kekelompokan (forming) yang bertujuan untuk menghilangkan kekakuan dalam hubungan antarpribadi dan terbentuknya rasa kekelompokan antar anggota. Kedua, tahap pancaroba dalam tahap ini tingkat efektivitas kelompok sudah akan mulai terlihat karena masing-masing anggota sudah mulai mengenal anggota kelompok dan sudah mengetahui kekuatan dan kelemahan masing-masing, anggota juga telah mengetahui peran 
dalam kelompok tersebut. Ketiga, tahap pembentukan norma yaitu bertujuan agar tercipta suasana penuh keharmonisan dalam kelompok dan menjadi sarana untuk pemecahan dan penyelesaian masalah. Keempat, tahap berprestasi dimana kelompok sudah memiliki keterbukaan komunikasi sehingga terdapat keluwesan dalam berinteraksi satu sama lain. dalam iklim kelompok yang seperti ini sinergi kelompok akan tercapai sehingga kelompok mampu menampilkan prestasi kerja yang optimal.

Selain layanan bimbingan kelompok ada beberapa teknik dalam konseling yang dapat meningkatkan kemampuan komunikasi siswa salah satunya Assertive training (latihan ketegasan). Menurut Alberti dan Emmons perilaku asertif atau asertivitas adalah suatu kemampuan yang dimiliki seseorang untuk mengungkapkan apa yang sedang ia rasakan, apa yang sedang dipikirkan, diinginkan, terhadap individu lain tetapi tetap dengan menjaga perasaan pribadi serta menghargai hak-hak dari pihak lain. Teknik latihan asertif adalah salah satu teknik dalam konseling behavioral yang diberikan pada individu yang mengalami kesulitan untuk menerima kenyataan bahwa menyatakan atau menegaskan diri adalah tindakan yang layak atau benar selama tidak menyakiti atau melanggar hak-hak orang lain.

Prinsip utama dari pelatihan asertif adalah bahwa orang harus dapat mengekspresikan perasaan dan pikiran secara bebas dan tepat tanpa ansietas. Teknik ini terdiri atas kontra pengkondisian ansietas dan memperkuat asertif (Samuel, 2015). Klien diajarkan bahwa semua orang mempunyai hak mengekspresikan diri. Klien kemudian mempelajari perbedaan antara agresif, pasif, dan asertif. Asertivitas adalah suatu kemampuan dimana seseorang bisa menyampaikan apa yang ada dalam perasaan dan pikirannya namun juga tetap memikirkan dan menjaga perasaan orang lain, dengan kata lain ia menyampaikan tidak secara agresif namun secara asertif.

Kasus dalam dunia pendidikan tentang kurangnya perilaku asertif ini seperti siswa yang tidak tegas ketika melihat temannya menyontek. Sehingga dia akan diam saja, menganggap semuanya baik-baik saja. Siswa yang seperti itu biasanya takut untuk mengungkapkan kebenaran, malu atau sungkan serta tidak percaya diri, takut dirinya dijauhi oleh teman-temannya. Sehingga untuk mengurangi perilaku pasif tersebut bisa menggunakan teknik assertive training yang dipandang mampu untuk melatih mengungkapkan pendapat sesuai dengan keinginan tanpa menyakiti orang lain. Selain itu, pemberian latihan perilaku asertif terbukti efektif dalam meningkatkan keterampilan komunikasi interpersonal siswa, mengurangi kebiasaan merekok, mengurangi tingkat bolos siswa, meningkatkan tanggungjawab, meningkatkan kepercayaan diri dan prestasi akademik siswa, meningkatkan 
keterampilan perilaku asertif dan mengurangi kecemasan interaksi sosial, peningkatan harga diri.

Hasil wawancara peneliti dengan salah satu guru BK terdapat siswa yang kurang memiliki keterampilan komunikasi khususnya ketika memiliki teman bermain atau teman berkumpul yang biasa disebut "geng" terdapat siswa yang tergabung dalam satu geng, namun pada dasarnya dia tidak senang dengan teman satu gengnya. Sehingga terjadilah perilaku saling menyindir. Tetapi anak yang tersindir tersebut tidak bisa menyampaikan ketidaksenangannya kepada temannya.

Apabila hal tersebut terus dibiarkan maka akan menimbulkan dampak yang tidak baik dan akan berdampak pada kondisi emosi seperti merasa tidak enak terhadap dirinya sendiri dan bahkan sering membenci dirinya sendiri karena tidak dapat mengatakan bila tidak suka, sedang tidak bisa bila diajak orang lain. Berdasarkan penjelasan tersebut siswa yang tidak bisa menyampaikan apa yang sedang dia rasakan perlu mendapat layanan bimbingan kelompok dengan teknik assertive training agar kemampuan berkomunikasinya dapat berkembang dengan baik. Alasan pemilihan layanan bimbingan kelompok karena dalam layanan tersebut megedepankan asas dinamika kelompok yang dapat menunjang keterampilan komunikasi. Sedangkan teknik assertive training dipilih agar siswa dapat mengatakan sesuatu sesuai dengan keadaan hatinya, sehingga tidak akan ada yang merasa dirugikan.

Adapun langkah-langkah dalam assertive training yang akan digunakan dalam penelitian ini ada 8, yaitu: (1) rasionalisasi strategi; (2) identifikasi keadaan yang menimbulkan persoalan; (3) membedaka perilaku asertif dan tidak asertif serta mengeksplor target; (4) bermain peran, pemberian umpan balik serta pemberian model perilaku yang baik; (5) melaksanakan latihan dan praktik; (6) mengulang latihan; (7) tugas rumah dan tindak lanjut; (8) terminasi

Beberapa penelitian terdahulu yang dipertimbangkan dalam penelitian ini yaitu penelitian Galih Wicaksono (2013) tentang meningkatkan kemampuan komunikasi interpersonal siswa melalui layanan bimbingan kelompok dengan teknik bermain peran memperoleh hasil bahwaada perbedaan signifikan pada skor kemampuan komunikasi interpersonal antara sebelum dan sesudah penerapan bimbingan kelompok teknik bermain peran. Pera Agustina (2016) tentang peningkatan kemampuan komunikasi interpersonal dengan menggunakan layanan konseling kelompok teknik assertive training menunjukkan hasil terdapat peningkatan kemampuan komunikasi interpersonal setelah diberi layanan konseling kelompok teknik assertive training. 
Adapun tujuan dalam penelitian ini adalah (1) untuk mengetahui efektivitas bimbingan kelompok dengan teknik assertive training dalam meningkatkan keterampilan komunikasi siswa SMK (2) untuk mengetahui adakah perubahan skor ketarampilan komunikasi sebelum dan sesudah diberikan perlakuan bimbingan kelompok dengan teknik assertive training.

\section{METODE}

Penelitian ini menggunakan pendekatakan kuantitatif (Wahyuningrum: 2020) dengan rancangan pre-experimental design. Desain yang digunakan adalah one-group pretest-posttest design (Sugiyono: 2010). Tujuan menggunakan desain one-group pretest-posttest design untuk mengetahui skor awal atau tingkat keterampilan komunikasi sebelum diberikan treatment yang kemudian setelah diberikan treatment akan diberikan post-test untuk mengetahui skor keterampilan komunikasi siswa.

Populasi dalam penelitian ini adalah semua siswa SMK Kesehatan Nusantara Kabupaten Pamekasan Provinsi Jawa Timur pada tahun ajaran 2020/2021 yang teridentifikasi memiliki tingkat ketarampilan komunikasi rendah. Sampel penelitian berjumlah 14 siswa yang dipilih dengan teknik purposive sampling. Instrumen penelitian yang digunakan dalam penelitian ini adalah skala keterampilan komunikasi dan wawancara. Skala pengukuran instrumen yang digunakan adalah model skala Likert. Skala Likert digunakan untuk mengukur sikap, pendapat, dan persepsi seseorang atau sekelompok orang tentang fenomena sosial (Sugiyono: 2010). Skala likert mempunyai lima kategori kesetujuan dengan skor 1-5. Item yang bersifat favorable $(+)$ mempunyai nilai 5-1, sedangkan item-item yang bersifat unfavorable (-) mempunyai nilai 1-5. Untuk lebih jelas ditulis pada tabel dibawah ini:

Tabel 1. Ketentuan Skor Skala Keterampilan Komunikasi

\begin{tabular}{cccccc}
\hline Pernyataan & SS & S & KS & TS & STS \\
\hline Positif & 5 & 4 & 3 & 2 & 1 \\
Negatif & 1 & 2 & 3 & 4 & 5 \\
\hline
\end{tabular}

Keterangan:

$\begin{array}{ll}\text { SS } & \text { : Sangat Sesuai } \\ \text { S } & \text { : Sesuai } \\ \text { KS } & \text { : Kurang Sesuai } \\ \text { TS } & \text { : Tidak Sesuai } \\ \text { STS } & \text { : Sangat Tidak Sesuai }\end{array}$


Sebelum skala disebar pada sampel penelitian, skala terlebih dahulu divalidasi. Angket diujicobakan di lapangan terbatas untuk mengetahui validitas dan reliabilitasnya. Instrumen penelitian dikatakan valid jika koefisien validitasnya $\geq 0,3$ sedangkan koefisien alpha yaitu $0,905 \geq 0,60$ maka instrumen penelitian dikatakan reliabel.

Teknik analisis data yang digunakan dalam penelitian ini adalah uji paired sample $T$ test. Uji ini merupakan bagian dari uji hipotesis komparatif atau uji perbandingan. Peneliti menggunakan uji ini karena ingin mengetahui perbedaan rata-rata dari dua sampel yang saling berhubungan atau berpasangan. Analisa data dengan menggunakan teknik paired sample T-test digunakan untuk menguji beda skor dari dua sampel yang berpasangan yaitu untuk melihat apakah ada perubahan tingkat keterampilan komunikasa pada saat pre-test dengan post-test.

\section{HASIL}

Gambaran Keterampilan Komunikasi Siswa Sebelum Diberikan Layanan Bimbingan Kelompok dengan Teknik Assertive Training

Untuk mengetahui kondisi awal keterampilan komunikasi siswa di SMK terlebih dahulu peneliti memberikan pretest berupa skala keterampilan komunikasi untuk mendapatkan skor awal. Skala tersebut diberikan kepada seluruh siswa kelas XII Keperawatan yang berjumlah 14 siswa.

Tabel 2. Hasil Pre-Test

\begin{tabular}{ccc}
\hline No & Subjek Penelitian & $\begin{array}{c}\text { Skor Keterampilan } \\
\text { Komunikasi }\end{array}$ \\
\hline 1 & O1 & 90 \\
2 & O2 & 109 \\
3 & O3 & 116 \\
4 & O4 & 122 \\
5 & O5 & 94 \\
6 & O6 & 91 \\
7 & O7 & 94 \\
8 & O8 & 94 \\
9 & O9 & 99 \\
10 & O10 & 100 \\
11 & O11 & 102 \\
12 & O12 & 106 \\
13 & O13 & 119 \\
14 & O14 & 121 \\
\hline
\end{tabular}




\section{Gambaran Keterampilan Komunikasi Siswa Setelah Diberikan Layanan Bimbingan Kelompok dengan Teknik Assertive Training}

Sesudah dilakukan perlakuan (treatment) yaitu melalui layanan bimbingan kelompok dengan teknik assertive training sebanyak empat kali pertemuan, setelah itu dilakukan post test untuk mengetahui meningkatnya keterampilan komunikasi siswa sesudah diberikannya perlakuan. Hasil post test selengkapnya dapat dilihat pada lampiran dan terangkum pada tabel berikut ini:

Tabel 3. Hasil Post-Test

\begin{tabular}{ccc}
\hline No & Subjek Penelitian & $\begin{array}{c}\text { Skor Keterampilan } \\
\text { Komunikasi }\end{array}$ \\
\hline 1 & O1 & 100 \\
2 & O2 & 110 \\
3 & O3 & 120 \\
4 & O4 & 120 \\
5 & O5 & 90 \\
6 & O6 & 94 \\
7 & O7 & 98 \\
8 & O8 & 97 \\
9 & O9 & 104 \\
10 & O10 & 108 \\
11 & O11 & 111 \\
12 & O12 & 107 \\
13 & O13 & 119 \\
14 & O14 & 122 \\
\hline
\end{tabular}

Berdasarkan Tabel 4 diketahui bahwa nilai rata-rata post test lebih tinggi daripada hasil rata-rata pre-test. Dengan begitu ada perubahan pada skor ketarampilan komunikasi setelah diberikan layanan bimbingan kelompok dengan teknik assertive training.

Tabel 4. Hasil Tes Paired $t$

\begin{tabular}{|c|c|c|c|c|c|}
\hline \multicolumn{6}{|c|}{ Paired Samples Statistics } \\
\hline \multirow{3}{*}{$\begin{array}{c}\text { Pair } \\
1\end{array}$} & & Mean & $N$ & $\begin{array}{c}\text { Std. } \\
\text { Deviation }\end{array}$ & $\begin{array}{c}\text { Std. Error } \\
\text { Mean }\end{array}$ \\
\hline & pre test & 104,07 & 14 & 11,506 & 3,075 \\
\hline & post test & 107,14 & 14 & 10,487 & 2,803 \\
\hline
\end{tabular}


Gambar 1. Diagram Batang Hasil Pre-Test dan Post-Test Skala Keterampilan Komunikasi

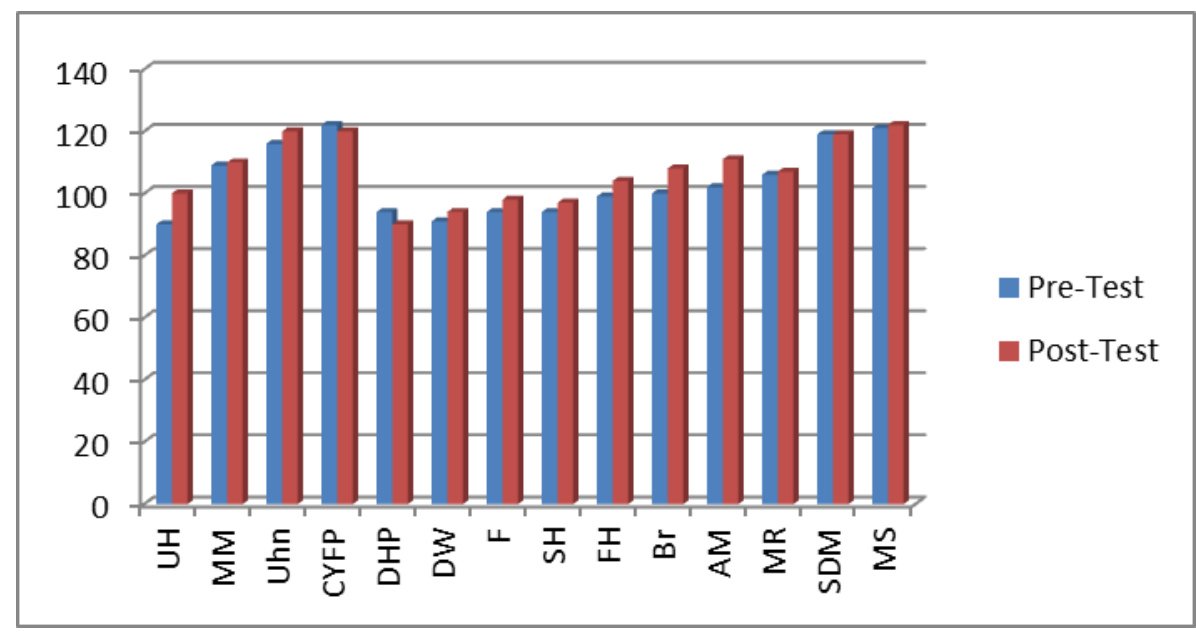

Dari diagram di atas dapat dilihat adanya perbedaan skor keterampilan komunikasi. Untuk grafik post-test secara umum lebih tinggi dibanding pre-test hal ini berarti terdapat perbedaan skor antara hasil pre-test dengan post-test setelah diberikan treatment bimbingan kelompok dengan teknik assertive training.

Tabel 5. Data Hasil Paired Differencess Melalui Paired Sample T Test

\begin{tabular}{|c|c|c|c|c|c|c|c|c|}
\hline & & & & $\begin{array}{r}9 \\
\text { Conf } \\
\text { Interva } \\
\text { Diffe }\end{array}$ & $\begin{array}{l}\% \\
\text { dence } \\
\text { lof the } \\
\text { ence }\end{array}$ & & & \\
\hline & Mean & $\begin{array}{c}\text { Std. } \\
\text { Diviation }\end{array}$ & $\begin{array}{c}\text { Std. } \\
\text { Error } \\
\text { Mean }\end{array}$ & Lower & Upper & $\underline{T}$ & $D f$ & $\begin{array}{c}\text { Sig. } \\
(2- \\
\text { tailed) }\end{array}$ \\
\hline $\begin{array}{c}\text { Pair } 1 \text { pre- } \\
\text { test post- } \\
\text { test }\end{array}$ & $\begin{array}{c}- \\
3,071\end{array}$ & 4,028 & 1,077 & $-5,397$ & $-0,746$ & $\begin{array}{c}- \\
2,853\end{array}$ & 13 & 0,014 \\
\hline
\end{tabular}

Dari hasil uji paired sample t test diketahui bahwa mean atau hasil rata-rata adalah sebesar -3,071 nilai ini adalah selisih antara rata-rata nilai pre-test dan post-test serta diketahui bahwa Sig. (2-tailed) sebesar 0,014. Dalam uji paired sample t test diatas diketahui bahwa nilai sig. (2-tailed) sebesar 0,014 yang berarti kurang dari 0,05 maka ada perbedaan yang bermakna dari hasil rata-rata pre-test dan post-test.

Dari hasil uji paired sample $\mathrm{t}$ test diatas, diketahui bahwa nilai t hitung adalah $-2,853$. $\mathrm{T}$ hitung bernilai negatif dikarenakan nilai rata-rata pre-test lebih rendah dibanding nilai ratarata post-test. Dalam konteks seperti ini nilai t hitung negatif dapat diartikan positif sehingga nilai t hitung menjadi 2,853 . 
Uji $\mathrm{T}$ dapat diperoleh dari hasil SPSS atau dapat dihitung manual dengan menggunakan rumus:

$$
t=\frac{\bar{d} \sqrt{n}}{s d}
$$

$d:$ selisih nilai dari sepasang data

$\bar{d}$ : nilai rata-rata dari nilai $d$

$s d$ : standar deviasi dari $d$

Tabel 6. Perbandingan Nilai Pre-Test Post-Test

\begin{tabular}{|c|c|c|}
\hline Pre-Test & Post-Test & Selisih \\
\hline 91 & 94 & -3 \\
\hline 94 & 98 & -4 \\
\hline 94 & 97 & -3 \\
\hline 99 & 104 & -5 \\
\hline 100 & 108 & -8 \\
\hline 102 & 111 & -9 \\
\hline 106 & 107 & -1 \\
\hline 119 & 119 & 0 \\
\hline 121 & 122 & -1 \\
\hline 90 & 100 & -10 \\
\hline 94 & 90 & 4 \\
\hline 109 & 110 & -1 \\
\hline 116 & 120 & -4 \\
\hline 122 & 120 & 2 \\
\hline \multicolumn{2}{|c|}{ Jumlah } & -43 \\
\hline \multicolumn{2}{|c|}{ Rata-rata } & $-3,07143$ \\
\hline
\end{tabular}

$$
\begin{aligned}
& s^{2}=16,22527 \\
& s=\sqrt{16,22527} \\
& =4,028061 \\
& t=\frac{-3,07143 \sqrt{14}}{4,028061} \\
& =-2,85304
\end{aligned}
$$


Dari hasil tersebut diketahui bahwa $\mathrm{t}$ hitung yang didapat melalui aplikasi SPSS dengan penghitungan manual menggunakan rumus didapatkan hasil yang sama yaitu $-2,853$. Diketahui t tabel dengan df 13 adalah sebesar 2,16 yang berarti nilai t hitung lebih besar dari $\mathrm{t}$ tabel maka ada pengaruh variabel bebas (X) terhadap variabel terikat (Y) atau hipotesis diterima.

Tabel 7. Paired Samples Correlations

\begin{tabular}{ccccc}
\hline \multicolumn{5}{c}{ Paired Samples Correlations } \\
& & $N$ & Correlation & Sig. \\
Pair 1 & pre test \& post test & 14 & 0,937 & 0,000 \\
\hline
\end{tabular}

Dari hasil uji paired samples correlations diketahui bahwa nilai korelasi sebesar 0,937 dan hampir mendekati angka 1 yang artinya nilai tersebut membuktikan adanya korelasi yang sangat kuat antara layanan bimbingan kelompok dengan teknik assertive training dalam meningkatkan keterampilan komunikasi. Serta diketahui nilai Sig. 0,000 yang diperoleh kurang dari 0,05_yang berarti ada perbedaan yang bermakna pada skor keterampilan komunikasi yang dilihat dari nilai pre-test dan post-test.

Tabel 8. Paired Samples Statistics

\begin{tabular}{|c|c|c|c|c|c|}
\hline \multicolumn{6}{|c|}{ Paired Samples Statistics } \\
\hline \multirow{3}{*}{$\frac{\text { Pair }}{1}$} & & Mean & $\underline{N}$ & $\begin{array}{c}\text { Std. } \\
\text { Deviation }\end{array}$ & $\begin{array}{c}\text { Std. Error } \\
\text { Mean }\end{array}$ \\
\hline & pre test & 104,07 & 14 & 11,506 & 3,075 \\
\hline & post test & 107,14 & 14 & 10,487 & 2,803 \\
\hline
\end{tabular}

Berdasarkan uji paired samples statistics diperoleh hasil rata-rata nilai pre-test sebesar 104,07 dan rata-rata nilai post-test sebesar 107,14. Diketahui bahwa rata-rata nilai post-test lebih tinggi dibanding rata-rata nilai pre-test yang menunjukkan bahwa ada perubahan skor yang bermakna dari hasil treatment yang berarti bimbingan kelompok dengan teknik assertive training efektif untuk meningkatkan keterampilan komunikasi siswa.

\section{PEMBAHASAN}

Hasil penelitian menunjukkan bahwa bimbingan kelompok dengan teknik assertive training dapat meningkatkan keterampilan komunikasi siswa kelas XII Keperawatan di SMK tahun ajaran 2020-2021. Ditunjukkan dengan nilai Sig. (2-tailed) sebesar 0,014<0,05 dan ditunjukkan dengan nilai t hitung $>\mathrm{t}$ tabel.

Berdasarkan wawancara yang telah dilakukan oleh peneliti kepada guru BK dan guru mata pelajaran di SMK menunjukkan bahwa bimbingan kelompok dengan teknik assertive 
training dapat meningkatkan keterampilan komunikasi siswa. Hal ini dapat dilihat dari wawancara guru BK yang menyatakan bahwa siswa kelas XII Keperawatan sudah ada peningkatan ketika diadakan presentasi. Selain itu, sifat yang suka memberikan pendapat secara langsung tanpa dipikir terlebih dahulu terdapat perubahan menjadi lebih sopan serta lebih memikirkan perasaan orang lain.

Peningkatan skor keterampilan komunikasi pada siswa kelas XII Keperawatan di SMK merupakan hasil dari perlakuan berupa bimbingan kelompok dengan teknik assertive training. Perlakuan tersebut dilakukan sebanyak 4 kali pertemuan dengan metode yang berbeda-beda tetapi dengan tetap mengikuti prosedur dalam teknik assertive training.

Pada pertemuan pertama hasil yang diperoleh ketika kelompok kecil diminta untuk mendiskusikan masalah yang terjadi dalam kehidupan sehari-hari, perwakilan kelompok diminta untuk maju dan melakukan role play dari permasalahan yang telah ditulis tersebut, dengan tujuan dari permasalahan tersebut siswa dilatih untuk menyelesaikannya dengan cara yang lebih asertif. Namun, siswa masih kesulitan untuk melakukan role play karena kurangnya rasa percaya diri, malu, dan takut. Sehingga pada pertemuan kedua, peneliti menggunakan metode yang berbeda yakni dengan meminta kelompok untuk mendiskusikan tentang pentingnya memiliki keterampilan komunikasi. Setelah itu perwakilan kelompok diminta untuk maju dan menjelaskan hasil diskusi bersama kelompok. Tujuan dari perlakuan ini, agar siswa lebih berani untuk mengungkapkan pendapatnya, serta melatih keterampilan komunikasi siswa di depan kelas. Pada pertemuan ketiga dan keempat, peneliti menggunakan simulasi kartu yang didalamnya sudah terdapat kasus yang harus diselesaikan oleh peserta didik. Kemudian setiap peserta didik diminta untuk maju secara bergantian dan mengambil kartu secara acak serta mencari penyelesaian dari kasus tersebut. Dengan metode ini semua sampel lebih tersentuh karena setiap peserta didik akan mendapat bagian untuk penyelesaian kasus. Dari metode tersebut didapat hasil yang jauh lebih baik dalam pengaplikasian assertive training, peserta didik jauh lebih mampu mengungkapkan perasaan dan pikirannya.

Penelitian tentang assertive training dan keterampilan komunikasi khususnya komunikasi interpersonal memang banyak dijadikan sebagai topik penelitian. Peneliti menemukan sedikitnya ada 2 penelitian yang pembahasannya hampir sama. Hanya saja terdapat perbedaan dalam hasil yang diperoleh. Berikut hasil penelitian yang dilakukan di SMK skor keterampilan komunikasi yang di dapat dari pre-test memiliki nilai rata-rata 104,07 dan nilai rata-rata post-test 107,14 sedangkan dalam penelitian lain diketahui nilai rata-rata hasil pre-test sebesar 71,08 dan nilai rata-rata post-test sebesar 85,29. Dalam penelitian yang lain juga diketahui nilai rata-rata hasil pre-test sebesar 115,3 dan nilai rata- 
rata post-test adalah 137,5. Dari ketiga penelitian didapatkan bahwa nilai rata-rata hasil posttest lebih tinggi dibanding nilai rata-rata pre-test yang berarti ada perubahan yang signifikan. Namun dari ketiga penelitian nilai rata-rata yang diperoleh berbeda. Hal ini menunjukkan bahwa keberhasilan perlakuan yang dilakukan dapat berbeda-beda interval peningkatannya bergantung kondisi serta permasalahan yang terjadi di lapangan.

\section{DAFTAR RUJUKAN}

Arumsari, Cucu Arumsari. Strategi Konseling Latihan Asertif Untuk Mereduksi Perilaku Bullying. Journal of Innovative Counseling. Tasikmalaya: 2017.

Aziz, Akhmad Rifqi. Efektivitas Pelatihan Asertivitas untuk Meningkatkan Perilaku Asertif

Siswa Korban Bullying. Jurnal Konseling dan Pendidikan. Jember, 2015.

Dharmayanti, Putri Ari. Jurnal Pendidikan dan Pengajaran. Bali: 2013.

Enjang. Komunikasi Konseling. Bandung: Penerbit NUANSA. 2009.

Faradita, Rizki Mutia. Dkk. Pengaruh Konseling Kelompok Dengan Teknik Assertive Training Terhadap Kemampuan Asertivitas Siswa Smpn Kota Bengkulu. Jurnal Ilmiah Bimbingan dan Konseling. Bengkulu: 2018.

Fauzan, Lutfi, dkk. Teknik-teknik Komunikasi Untuk Konselor. Malang: Universitas Negeri Malang. 2008.

Gladding, Samuel T. Konseling Profesi yang Menyeluruh. Jakarta: PT Indeks. 2015.

Hartinah, Sitti. Konsep Dasar Bimbingan Kelompok. Bandung: PT Refika Aditama. 2017.

Ituga, Almuhaimin Sarnav. Efektivitas Teknik Latihan Asertif Untuk Meningkatkan Internal Locus Of Control Siswa dalam Belajar. Jurnal Psikologi Pendidikan \& Konseling. Makassar: 2017.

Katsir, Ibnu. Tafsir Ibnu Katsir. Jakarta: Pustaka Imam Syafi’i. 2016.

Kementerian Agama RI. Mushaf Al-Jalalain Mushaf Al-Qur'an Terjemahan Per Kata dan Tafsir Jalalain Per Kalimat. Bekasi: Pustaka Kibar. 2014

Khairani, Aulia, dkk. Jurnal Ilmiah Mahasiswa Bimbingan Dan Konseling. Banda Aceh: 2017.

Mashudi, Farid. Psikologi Konseling. Jogjakarta: IRSiSoD. 2013.

Pontoh, Widya P. Peranan Komunikasi Interpersonal Guru Dalam Meningkatkan Pengetahuan Anak. Jurnal Acta Diurna. Manado: 2013

Prayitno. Dasar-Dasar Bimbingan dan Konseling. Jakarta: PT Rineka Cipta. 2013.

Supriatna, Mamat. Bimbingan dan Konseling Berbasis Kompetensi. Jakarta: PT Raja Grafindo. 2014.

Sugiyono. Metode penelitian kuantitatif dan R dan D. Bandung: Alfabeta. 2010.

Tohirin. Bimbingan dan Konseling di Sekolah dan Madrasah (Berbasis Integrasi. Jakarta: PT Raja Grafindo Persada. 2014.

Tuti, Meiri Dias. Career Planning. Yogyakarta: CV MFA. 2019.

Wahyuningrum, Sri Rizqi. Statistika Pendidikan (Konsep Data dan Peluang). Surabaya: Jakad Media Publishing. 2020.

Wijaya, Ida Suryani. Komunikasi interpersonal dan iklim komunikasi dalam organisasi. Jurnal Dakwah Tabligh. Samarinda: 2013.

Willis, Sofyan S. Willis. Konseling Individual Teori dan Praktek. Bandung: Alfabeta. 2004.

Zuhara, Evi. Efektivitas teknik sosiodrama untuk meningkatkan komunikasi interpersonal siswa (penelitian kuasi eksperimen kelas X di SMA Kartika Siliwangi 2 Bandung Tahun Ajaran 2013/2014). Jurnal Ilmiah Edukasi. Bandung: 2015. 